\title{
CONSIDERACIONES GENEALÓGICAS PARA LA PRÁCTICA CLÍNICA SISTÉMICA: ALCANCES EN TORNO A LA SUBJETIVIDAD
}

\author{
GENEALOGICAL CONSIDERATIONS FOR SYSTEMIC \\ CLINICAL PRACTICE: SCOPE AROUND SUBJECTIVITY
}

\author{
José Carreón Catalán* \\ Universidad de Chile \\ Santiago-Chile \\ Sergio Padilla Garrido \\ Universidad de Chile \\ Santiago-Chile \\ Recibido diciembre de 2020/Received December, 2020 \\ Aceptado junio de 2021/Accepted June, 2021
}

\begin{abstract}
RESUMEN
En este artículo se presenta al lector la genealogía desde un punto de vista teórico-clínico. El propósito es conectar una aproximación genealógica para y desde la práctica clínica sistémica en vista a los procesos de subjetivación. La genealogía, como guía metodológica o disposición terapéutica, permitiría contribuir a la toma de distancia crítica necesaria para el encuentro terapéutico. También, prodigar un cuidado hacia el otro, como ética de la libertad, al revalorizar al sujeto en torno a su sufrimiento.
\end{abstract}

Palabras Claves: Nietzsche, Foucault, genealogía, subjetividad, psicoterapia sistémica.

\begin{abstract}
In this article, genealogy is presented to the reader from a theoretical-clinical point of view. The purpose is to connect a genealogical approach to and from systemic clinical practice in view of the processes of subjectivation. Genealogy, as a methodological guide and/or therapeutic disposition, would allow to contribute to the critical distance necessary for the therapeutic encounter. Also, lavish care for the other, as an ethic of freedom, by revaluing the subject around their suffering.
\end{abstract}

Key Words: Nietzsche, Foucault, genealogy, subjectivity, systemic psychotherapy.

\section{INTRODUCCIÓN}

En Ecce homo, Nietzsche escribe en retrospectiva acerca de la Genealogía de la moral:

"Siempre hay un comienzo que tiene que inducir a error, y este comienzo es frío, científico, e incluso irónico; con toda intención se sitúa en primer plano y se produce una demora. Poco a poco, aumenta la agitación; aparecen relámpagos aislados; desde la lejanía se dejan oír con sordos gruñidos verdades muy desagradables. Al fin se adquiere un ritmo feroz, en el que todo se precipita con una extraordinaria tensión. Por último, entre 
espantosos estampidos, se van haciendo visibles a través de espesas nubes nuevas verdades que aparecen de una en una"1 (Nietzsche, 2003b, p. 133).

La genealogía se encarga del problema de la verdad y su origen. Foucault (2008a) retoma en su escrito de 1971 Nietzsche, la genealogía, la historia, la metodología genealógica nietzscheana como un arte de la paciencia, propia del archivista o documentalista, para esbozar la génesis o historia de un fenómeno o valor. La genealogía mira la historia no de forma lineal, sino con sentidos antagónicos, múltiples y divergentes, pero conectados desde la confrontación. La genealogía es el arte de la demora: observa y escucha con distancia. Recupera, parafraseando el trabajo de Nietzsche, la historia como potenciación de la vida y no como mera recopilación de sucesos inequívocos ${ }^{2}$.

A nuestro juicio la genealogía como método, actitud, aproximación o guía no ha sido del todo advertida, menos profundizada, ignorando la potencialidad de su contribución al campo clínico e incluso su afinidad y convergencia con algunos de los modelos sistémicos más contemporáneos. Con el arribo del postmodernismo y los aportes del pensamiento postestructuralista francés, la terapia como construcción social (McNamee y Gergen, 1996) enfatizó el tránsito subjetivo del "contexto" de Bateson al "texto" y la deconstrucción de Derrida (Bertrando y Toffanetti, 2004), el análisis de las prácticas de poder de Foucault, así como la idea de los "juegos de lenguaje" de Wittgenstein (Bertrando, 2011; Limón, 2005; Tarragona, 2013; Vicencio, 2013).

La incorporación de Michael White respecto del análisis del poder de Foucault y el rendimiento de conceptos como "resistencia", "relatos dominantes", "relatos alternativos" y "acontecimientos extraordinarios" (White y Epston, 1993), permitió comprender la terapia narrativa como una terapia deconstructiva (White, 2004). La terapia también fue reconocida como arte de la conversación (Anderson y Goolishian, 1988, 1996; Anderson, 2007, 2012). La noción más actual es la terapia dialógica (Bertrando, 2011; Hermans, 2001; Rober, 2005; Seikkula, 2011). Los terapeutas sistémicos se comprometieron con la terapia como un encuentro de narraciones y conversaciones. Los pacientes fueron concebidos como sujetos lingüísticos creadores de significados.
La valiosa metáfora narrativa permitió entender, en términos de subjetividad, al sujeto como texto. Sin embargo, en el presente artículo quisiéramos resaltar los aportes de la genealogía para el campo terapéutico sistémico, a partir de precisiones teóricas y de pistas metodológicas clínicas, considerando no solo la metáfora narrativa, sino incorporando sucintamente el trabajo de Marcelo Pakman $(2011,2014)$. Este ha permitido entender las experiencias terapéuticas -espacios micropolíticos de producción de subjetividad- no solo en función de procesos de significación y la primacía del lenguaje. La psicoterapia crítico-poética posee una preocupación por la singularidad humana, la imaginación y la dimensión del sentido. La genealogía es afín a ambas propuestas.

Nos interesa sobre todo crear un puente entre la genealogía y la psicoterapia sistémica relacional a propósito de la producción de subjetividad. Como sostienen Guattari y Rolnik (2019), no es equiparable la individualidad e identidad con la subjetividad. Esta última no alude a lo intrapsíquico. Los individuos están entrelazados y atravesados por múltiples componentes de la subjetividad. Excede a toda totalización y centralización en un individuo. La subjetividad es manufacturada y está en constante circulación social. En un individuo se experimentaría entre dos extremos "una relación de alienación y opresión [...], o una relación de expresión y de creación, en la cual el individuo se reapropia de los componentes de la subjetividad" (Guattari y Rolnik, 2019, p. 48). El primer modo se padece como sometimiento, el segundo como reapropiación y singularización.

El espacio terapéutico dispone oportunidades para la singularidad, desafiando críticamente tanto las prácticas terapéuticas como la formación de identidad, operando sobre los dos aspectos de la subjetividad: sujeción y subjetivación (Morales, 2010). Es necesario mirar la subjetividad circundante en torno al sufrimiento. Es una constante la posibilidad del derrumbamiento, el asedio de la discontinuidad del sentido y la trama identitaria (Zamorano, 2014).

La genealogía podría ser una puerta de entrada estética y ética en dirección al poder de las historias y las historias de poder de las y los consultantes. Historias de sentido. La responsabilidad de acoger esas historias recae en las y los terapeutas. Sin olvidar que el poder de poner en evidencia los relatos proviene de quien consulta 
y que: "La historia es importante, pero el proceso lo es más" (Rodríguez-Bustamante, 2016, p. 40).

Por consiguiente, se propone que la exploración genealógica prepararía un terreno fértil para desestabilizar la subjetividad, a modo de cartografía a tener en cuenta en cualquier movimiento de emancipación singular (Guattari y Rolnik, 2019). Así, se abordará primero la tarea de la genealogía a partir de algunas precisiones teóricas. Luego, la psicoterapia como una tecnología de poder-saber inherente a los procesos de subjetivación. Por último, cómo la metáfora narrativa y la psicoterapia crítico-poética poseen puntos de encuentro y diferencias al introducir una aproximación genealógica en el trabajo clínico.

\section{LA GENEALOGÍA Y EL PROBLEMA DEL ORIGEN}

\author{
“...antes se romperá una pierna que \\ romperse una palabra" \\ Friedrich Nietzsche. Aurora.
}

Comencemos con la tarea de la genealogía:

\begin{abstract}
"De aquí deriva para la genealogía una tarea indispensable: percibir la singularidad de los sucesos, fuera de toda finalidad monótona; encontrarlos allí donde menos se espera y en aquello que pasa desapercibido por no tener nada de historia -los sentimientos, el amor, la conciencia, los instintos-; captar su retorno, pero en absoluto para trazar la curva lenta de una evolución, sino para reencontrar las diferentes escenas en las que han jugado diferentes papeles; definir incluso el punto de su ausencia, el momento en el que no ha tenido lugar" (Foucault, 2008a, p. 7-8).
\end{abstract}

Foucault (2008a) problematiza acerca de la naturaleza histórica del origen y su relación con la verdad. El color del genealogista no es el azul, es el gris. No mira hacia los ideales azules del cielo, sino el gris de las escrituras, documentos y archivos. De ahí que la exigencia sea para el historiador buscar las "pequeñas verdades sin apariencia" (Nietzsche, 2011b) y la búsqueda no del "origen" sino de las "meticulosidades y azares de los comienzos" (Foucault, 2008a). No se rechaza la historia, la genealogía se opone al método de la historia tradicional y la metahistoria, aquella que rechaza los eventos singulares a favor de la historia continua y oficial.
Nietzsche rechaza la búsqueda del origen si ello supone el encuentro con la esencia e identidad de una cosa o fenómeno, por ejemplo, la moral (como si se tratara de una sustancia replegada sobre sí misma). Es un prejuicio la esencia en el origen: "A medida que aumenta la introspección en el origen, aumenta la insignificancia del origen" (Nietzsche, 2011a, p. 105) $)^{3}$. Se cuestiona el origen como lugar de la verdad fija, centrada, estable en su misma identidad, desconociendo las fuerzas que recubren su procedencia múltiple. La historia busca máscaras a revelar, la genealogía sucesos en pugna. Es el enfrentamiento y la unidad del desencuentro lo que debe mirarse: "Lo que se encuentra al comienzo histórico de las cosas, no es la identidad aún preservada de su origen -es la discordia de las otras cosas, es el disparate" (Foucault, 2008a, p. 10).

La genealogía incorpora un robusto "no". Su intención no es superar el olvido y recuperar una continuidad perdida en el tiempo retrotrayéndose al ayer. Su preocupación es el tiempo, pero no para desmadejar la verdad a modo de su reconducción. Su motivación no es mostrar que el pasado está vivo en nuestro presente. Su interés si está en el pasado, pero no para hilar y enderezar la historia en tiempos lineales, a modo de una gran continuidad monótona, sino para "reencontrar las diferentes escenas" y "percibir la singularidad de los sucesos". El "sî" del análisis genealógico proviene un método severo (Foucault, 2008a) ${ }^{4}$. Este método se sumerge en los pliegues y fisuras, inestables de la historia, para remover la aparente objetividad de las cosas.

Para Foucault, la genealogía recupera saberes descontados, locales, discontinuos, no legitimados, contra el conocimiento y las ciencias que ordenan y jerarquizan en nombre de un conocimiento histórico verdadero. Pero no para ser más exactos, sino para recuperar las experiencias restadas por el saber, "Se trata de la insurrección del saber" (Foucault, 2001b, p. 22). Según Dreyfus y Rabinow (2001), Foucault el genealogista no está indignado como Nietzsche, pero la tarea es "destruir la primacía de los orígenes, las verdades intocables. Busca destruir las doctrinas del desarrollo y del progreso" (p. 137-138). Luego, se ocupa del conflicto y la lucha de voluntades: prácticas, discursos, perspectivas.

Deleuze (2008) agrega algo más. En su libro sobre Nietzsche y la filosofía, piensa la genealogía como una filosofía crítica que se acerca no como mera reacción, sino como, desde una perspectiva 
nietzscheana, una acción que se despliega con la fuerza del "martillo" pero no para destruir. La genealogía no solo interpreta, sino que simultáneamente realiza valoraciones:

\begin{abstract}
"Genealogía quiere decir a la vez valor del origen y origen de los valores. Genealogía se opone tanto al carácter absoluto de los valores como a su carácter relativo o utilitario. Genealogía significa el elemento diferencial de los valores de los que se desprende su propio valor. Genealogía quiere decir pues origen o nacimiento, pero también diferencia o distancia en el origen. Lo noble y lo vil, lo alto y lo bajo, tal es el elemento propiamente genealógico o crítico. Pero así entendida, la crítica es al mismo tiempo lo más positivo. El elemento diferencial no es crítica del valor de los valores, sin ser también el elemento positivo de una creación" (Deleuze, 2008, p. 9).
\end{abstract}

La genealogía no critica por el goce de destruir, sino por el placer de crear. Es una acción. Deleuze (2008) expone que los valores suponen perspectivas de valoración, él dirá "puntos de vista de apreciación". El valor en ese sentido apunta a un peso y una mirada, el peso de la mirada que estima y juzga la vida, las relaciones, la existencia, en definitiva, valorar implica formas de ser y modos de vivir. De ahí la relevancia de la creación genealógica. La genealogía sería una forma de romper el sometimiento de los saberes históricos unitarios y científicos, liberando el conocimiento y la memoria disidente, suscitando oposición y combate, para la reactivación de saberes locales (Foucault, 2001b).

La genealogía foucaulteana persigue precisamente el conflicto inherente y resultante de estar vivos y vivir en sociedad. Porque de ello nacen formas de ser legítimas e ilegítimas, relaciones de poder que habilitan espacios de dominación y subyugación. Por lo mismo, su interés genealógico no está en la búsqueda del origen, sino en la "procedencia" o Herkunft, tampoco en la gran verdad, sino su "emergencia" o Entstehung (Foucault, 2008a). Este método mostrará que los sujetos no existen previo a la lucha de fuerzas. Los sujetos emergen en el campo de batalla, solo allí. No hay una realidad más verdadera, es tal cual aparece, eso es lo que revela la genealogía (Dreyfus y Rabinow, 2001).

Para Foucault (2008a) la procedencia se ocupa no de fundar el origen, sino de remover lo que parecía inmóvil, así, al fragmentar una supuesta identidad conforme a sí misma, se desestabiliza el sedimento de lo erguido como verdad inmóvil, mientras que la emergencia da cuenta de la aparición singular: el surgimiento. Así, mientras que la "procedencia se enraíza en el cuerpo", la "emergencia se produce siempre en un determinado estado de fuerzas": "Mientas que la procedencia designa la cualidad de un instinto, su grado o su debilidad, y la marca que este deja en un cuerpo, la emergencia designa un lugar de enfrentamiento" (Foucault, 2008a, p. 16).

Precisamente, la genealogía se abocará en dar cuenta de los juegos de dominación, el enfrentamiento de fuerzas que esculpen un cuerpo que padece la historia literalmente en términos fisiológicos: actúa sobre el sistema nervioso. El cuerpo será el lugar de inscripción de los sucesos y eventos de la vida (Foucault, 2008a). Por lo mismo, ese cuerpo, podríamos decir con Foucault, sería la fuente y procedencia del devenir de la historia: " $\mathrm{La}$ genealogía, como el análisis de la procedencia, se encuentra por tanto en la articulación del cuerpo y la historia. Debe mostrar al cuerpo impregnado de historia, y a la historia como destructor del cuerpo" (Foucault, 2008, p. 15).

La lucha de fuerzas también es la lucha por el sentido. Pero no desde un sujeto intencional, menos por un destino teleológicamente fundado, sino por el azar de la vida o de la vida misma como azar ${ }^{5}$. La vida es voluntad de poder. Esto se relaciona con la idea nietzscheana de libertad, en tanto sentimiento de superioridad y felicidad que conlleva esa victoria agonística: "La consciencia de que se acrecienta el poder; que queda superada una resistencia" (Nietzsche, 2010b, p. 22) ${ }^{6}$. La vida es lucha de fuerzas. Por lo mismo, Deleuze (2008) plantea lo siguiente: "Nunca encontraremos el sentido de algo (fenómeno humano, biológico, incluso físico), si no sabemos cuál es la fuerza que se apropia de la cosa, que la explota, que se apodera de ella o se expresa en ella" (p. 10).

La historia para Nietzsche es precisamente la historia de una apropiación de una voluntad que domina. Pero en el origen se entrelaza lo bajo, vil e incluso el error ${ }^{7}$. Se trata de una variación de los sentidos en términos de dominación (Deleuze, 2008). Siempre existen "constelaciones de sentidos", múltiples y en conflicto. Hermenéuticamente, "el devenir de la humanidad es una serie de interpretaciones. Y la genealogía debe ser su historia" (Foucault, 2008a, p. 18) . $^{8}$ 
El análisis de la emergencia debe señalar los juegos de poder, la lucha y el combate agonístico fruto de las dominaciones y el azar. La procedencia localiza heridas, hendiduras, incisiones, tajos, acciones y procesos históricos-discursivos sobre y en el cuerpo: mil sucesos perdidos. Aún más, la genealogía mira el silencio de los acontecimientos. Incluso en el silencio existen grados de fuerzas, pluralidad de fuerzas que coexisten e intentan dominar como puntos de vistas diversos. "Los acontecimientos más grandes - no son nuestras horas más estruendosas, sino las más silenciosas" (Nietzsche, 2007b, p. 111) $)^{9}$. La genealogía se encamina en su búsqueda.

Para Deleuze (2008) el arte de la genealogía incorpora la interpretación en la medida que esta valora y pesa los acontecimientos, no para destruir, al contrario, para crear. Para Foucault (2008a) el saber no está hecho para comprender sino para hacer tajos. Una aproximación genealógica integra estas consideraciones y actitudes al momento de mirar el juego de fuerzas que luchan entre sí sobre el cuerpo: un saber para crear. Por consiguiente, "puntos de vista de apreciación" que en psicoterapia contribuirían a fisurar la subjetividad y ampliar nuevos modos de ser. La genealogía permitiría mirar los procesos de subjetivación como análisis de la procedencia y la emergencia, produciendo un movimiento telúrico en torno a la subjetividad y el sufrimiento históricamente petrificados por las palabras.

\section{PROCESOS DE SUBJETIVACIÓN Y PSICOTERAPIA}

De acuerdo con Dreyfus y Rabinow (2001): "El genealogista es un diagnosticador que se concentra sobre las relaciones entre el poder, el saber y el cuerpo en la sociedad moderna" (p. 131). Foucault (2001a) declara en retrospectiva que el propósito de su trabajo -arqueológico, genealógico, histórico- no fue una analítica del poder "ha sido crear una historia de los diferentes modos a través de los cuales, en nuestra cultura, los seres humanos se han convertido en sujetos" (p. 241). Según él, tres son las formas de objetivación en donde los seres humanos se sujetan: toda investigación que se autodesigna un estatuto científico, las prácticas divisorias del sí mismo o de exclusión de otros seres humanos, por último, modos por los que las personas se transforman a sí mismos en sujetos ${ }^{10}$.

Hay una relación entre subjetividad y relaciones de poder. Para mirar ese nexo será necesario atender a la naturaleza empírica de las relaciones de poder y el enfrentamiento de fuerzas antagónicas en lugar de racionalidades internas del poder (Foucault, 2001a). En estos enfrentamientos de fuerzas inevitablemente se producen actos de resistencias, porque las constelaciones de sentido son plurales y los puntos de apreciación diversos.

En Vigilar y castigar, Foucault (2012) realiza una genealogía del nacimiento de la prisión en la que analiza nuevas relaciones de poder a propósito del castigo. El cuerpo está inmerso en un campo político. En las sociedades disciplinarias el poder no opera únicamente sobre el cuerpo sino "para herir en él algo que no es el cuerpo mismo" (Foucault, 2012, p. 20). Una nueva "economía política del cuerpo", sutil y velada, ausente de exposición teatral, recae también sobre el alma. Este movimiento transita de la esfera pública a la íntima y privada, creando una subjetividad particular: sujetos disciplinados y obedientes. Dicha genealogía, diríamos con ByungChul Han, señala que el poder es más espacioso que la violencia y que el poder brilla por su ausencia (Han, 2019).

El poder retira su expresión clásica coercitiva y jerárquica de espacios abiertos. Antes que negativo -represivo, restrictivo, opresivo, autoritario-el poder es positivo y productivo. Este es el paso que Foucault identifica en su Historia de la sexualidad desde un mundo político en el que impera la ley de la espada del soberano, a una sociedad normalizadora en la que reina la ley de la norma (Foucault, 2005). Es decir, el desplazamiento del derecho de dar muerte hacia un poder y preocupación por dar vida, lo que el filósofo francés identificó como "biopolítica" (Foucault, 2001b, 2005). Nuevas tecnologías y espacios microfísicos del poder surgen orientados a administrar la vida: medicina social, psiquiatría, prisión, psicoanálisis, entre otras disciplinas y ciencias humanas de carácter positivista.

El poder crea no solo cuerpos dóciles sino formas de vida. Las relaciones de poder engendran campos de saber y a partir de ese entramado sujetos. No solo van de la mano, sino que se trata de fuerzas inmanentes a la práctica social. Estructuran y moderan las relaciones humanas, definiendo lo humano como experiencia singular, a partir de ciertos modos de conocimiento y prácticas socioculturales por sobre otras. Foucault (2012) es enfático al escribir que no hay relaciones de poder que no funden campos de saber, ni campos discursivos de saber por fuera de las relaciones de poder: 
"Hay que admitir más bien que el poder produce saber (y no simplemente favoreciéndolo porque le sirva o aplicándolo porque sea útil); que poder y saber se implican directamente el uno al otro; [...] Estas relaciones de "podersaber" no pueden analizarse a partir de un sujeto de conocimiento que sería libre o no en relación con el sistema de poder sino que hay que considerar, por el contrario, que el sujeto que conoce, lo objetos que conocer y las modalidades de conocimiento son otros tantos efectos de estas implicaciones fundamentales del poder-saber y de sus transformaciones históricas" (Foucault, 2012, p. 37).

El poder se estabiliza generando hábitos y formas de comportamiento en un nivel simbólico, dejando huellas significativas en los sujetos y produciendo configuraciones de sentido y realidad (Han, 2019). El poder crea continuidades de sentidos comprensibles. Esta cotidianidad de las prácticas, podríamos decir micropolíticas (Pakman, 2011), generan hábitos relacionales de dominación e identidad. Ahora bien, no hay qué ni a quién liberar porque no existe nada por fuera del poder-saber, salvo resistirse como fuerza. El poder no es un asunto moral, aunque su expresión lo es.

Vida y poder, política y vida, no son ámbitos separados (Lemm, 2015). La vida es poder: voluntad de poder. Su inmanencia es tal en el sentido de que la vida misma es una lucha (agon) y fuerzas en pugna constantes, que podemos hablar de una lógica empírica de las relaciones de poder. El poder es un entramado de la cotidianeidad. Para Foucault (2001a) en el agon mismo de la vida política lo que está en juego es el tipo de respuesta ante la pregunta “QQuiénes somos?”:

"Esta forma de poder se aplica a la inmediata vida cotidiana que categoriza al individuo, le asigna su propia individualidad, lo ata en su propia identidad, le impone una ley de verdad sobre sí que está obligado a reconocer y que otros deben reconocer en él. Es una forma de poder que hace sujetos individuales. Hay dos significados de la palabra sujeto: por un lado, sujeto a alguien por medio del control y de la dependencia y, por otro, ligado a su propia identidad por conciencia o autoconocimiento. Ambos significados sugieren una forma de poder que subyuga y sujeta" (Foucault, 2001a, p. 245).
Ser sujeto es ser sometido. Responder: “¿Quiénes somos?" o inquietarse por lo que somos es una manera de aproximarse a las relaciones de poder-saber, en las que el poder no es solamente impuesto restrictivamente de arriba hacia abajo, sino que se haya distribuido en una horizontalidad espacial en donde los propios sujetos relacionales son partícipes de su sumisión, reforzando a su vez, a partir de una elección libre sin la necesidad de violencia, la red de sujeción y el poder del poder ${ }^{11}$. Foucault (2001a) mismo dirá que el poder se ejerce en sujetos libres, claro con posibilidad de resistencia, de lo contrario, será dominación absoluta. El poder es inevitable.

La psicoterapia es un terreno para la producción de subjetividad, no escapa a la red de poder-saber. Como tal se conecta con el poder pastoral, mediante prácticas como la confesión. Foucault (2006) genealógicamente observa cómo la política moderna actual, la biopolítica, es heredera del poder pastoral. Este se preocupa por la salvación del rebaño: la especie humana. Foucault (2005, 2006) identifica tecnologías de individualización pastoral: la primera una servidumbre del rebaño total excluyendo todo egoísmo (yo), segundo, la producción de una verdad secreta interior. El pastor asegura la obediencia mediante la identificación de esta verdad individualizada, pero excluida del resto. La individualización de la "existencia del ser humano como animal viviente es entregada así a los discursos de poder-saber de las nuevas ciencias humanas y naturales" (Lemm, 2013, p. 175). La administración vital del rebaño y el alma, cambia hacia la población y el cuerpo en la biopolítica.

De gran interés para este escrito son los mecanismos individualizadores a través de los cuales las personas se constituyen a sí mismos, a partir de un saber, en sujetos. Dichos mecanismos Foucault (2008b) los denominaría "tecnologías del yo", basándose en el principio griego sobre el cuidado de si $^{12}$. Las tecnologías del yo como procesos de subjetivación hacen referencia a aquellas objetivaciones discursivas de saberes y racionalidades, a partir de estas el sujeto opera sobre sí mismo acciones de autotrasformación y automodelación psíquica, emocional, conductual y corporal. Se trata de mecanismos por los que el ser se constituye históricamente en experiencia válida, factual y situada (Vignale, 2014), entendiendo como experiencia la correlación en una cultura, entre campos de saber, normatividad y subjetividad (Foucault, 1987). 
La psicoterapia es parte de esa experiencia tecnológica como forma cultural ${ }^{13}$. Utiliza técnicas de poder racionalmente: opera como una tecnología del yo. Emplea prácticas discursivas acerca de la verdad. Su saber, gestionado mediante prácticas terapéuticas, ejercicios microfísicos de poder, promueven formas de objetivación, en definitiva, formas de vida. Estas prácticas son una expresión sofisticada y secular de las tecnologías de control gubernamental de orden religioso, la confesión y el autoexamen, ahora insertas en la racionalidad discursiva médico-psiquiátrica. La psicoterapia también es una experiencia psicopolítica ${ }^{14}$. Por consiguiente, toda experiencia y acontecimiento de carácter clínico, no solo no es objetivo, sino que no es puro ni está por fuera del poder. Las estrategias de poder son inmanentes a la voluntad de saber (Foucault, 2005).

Pero en el hacer el sujeto permanece abierto ${ }^{15}$. Los procesos de subjetivación no solo promueven una visión de lo humano, sino que crean lo humano. Las relaciones de poder-saber desplegadas en un discurso (teoría) y su materialidad (práctica clínica), nos atraviesan y constituyen, sujetando las identidades humanas mediante una voluntad de saber que genera múltiples continuidades de sentidos. La psicoterapia es un espacio abierto de poder porque este no es solo un fenómeno de la interioridad y la subjetividad, sino intersubjetivo y relacional: "El poder capacita al yo para recobrarse a sí mismo en el otro. Genera una continuidad del sí mismo" (Han, 2019, p. 18). La genealogía contribuiría a ese recobrarse afectando al sujeto.

Para Foucault (1994) el sujeto de conocimiento cartesiano, típico de las tradiciones científicas, actúa sobre la verdad, pero esta no actúa sobre el sujeto. En la práctica del cuidado de sí mismo, el otro es indispensable para que esa preocupación e inquietud alcance a su objeto: el yo. Sabemos que en estas prácticas el otro, en este caso el o la terapeuta, ocupa un rol mediador desde una ética que afecta al sujeto según "un saber que tiene por efecto y por función modificar el ser del sujeto. Es preciso que esta verdad afecte al sujeto" (Foucault, 1994, p. 80). Así, la psicoterapia como expresión genealógica no informa a los sujetos, todo lo contrario, desestabiliza la subjetividad y donaría espacio para la creatividad.

La psicoterapia puede ir en línea con la idea que Foucault toma de Nietzsche a propósito de hacer de la propia vida una obra de arte. Una ética de la libertad que Foucault llama "estética de la existencia" (Lemm, 2013). Sostenemos que una psicoterapia desde un punto de vista relacional, es capaz de habilitar espacios de poder, soberanía personal y libertad, resistiéndose a los vectores y lineamientos cotidianos de la normalización biopolítica y micropolítica. Mediante un rastreo genealógico desde nuestras prácticas psicoterapéuticas, es posible tomar distancia para afectar la subjetividad.

\section{ALCANCES GENEALÓGICOS PARA UNA PRÁCTICA SISTÉMICA}

La práctica psicoterapéutica bien se trata de una práctica genealógica. En el encuentro terapéutico se aprende que más allá de los relatos hay cuerpos que experimentan y padecen los sucesos de sus historias, el mundo los toca. Esas inscripciones pertenecen a una temporalidad móvil que se reactualiza en el presente. La genealogía revisita esas historias de sentido encarnadas y muchas de ellas silenciosas. En cierto modo atenta a la continuidad/ discontinuidad de la experiencia vivida; al quiebre de sentido relacional en tanto posibilidad de apertura a la diferencia (Zamorano, 2014).

En cuanto a la analogía del sujeto como texto, White y Epston (1993) plantean que para entender nuestras vidas las experiencias deben relatarse. Los significados de esos relatos disponen de una continuidad de sentido. No obstante, la narración paga un alto precio: "Una narración no puede abarcar jamás toda la riqueza de nuestra experiencia vivida" (White y Epston, 1993, p. 28). Así es como la "relativa indeterminación" de la experiencia compele al narrador a comprometerse con la asignación de significado y la representación de los relatos. De ahí la terapia como reescritura de vida de relatos alternativos, ya que no todas las narraciones nos representan y a veces están subyugadas por relatos dominantes. Esa es precisamente la dirección de la genealogía.

Asimismo, Pakman (2011) plantea que los espacios que habitamos propician la construcción de guiones identitarios, en ocasiones estereotipados o guiones micropolíticos necesarios, ejerciendo una continuidad de sentido incluido sufrimiento. Pero la textura sensual indeterminada de la experiencia vívida no es capturable del todo por los procesos de significación y la representación del lenguaje. La micropolítica dominante es asediada por la dimensión del sentido en exceso a las palabras. El 
evento poético propuesto por Pakman $(2011,2014)$ se orienta a la dimensión del sentido, fisurando momentáneamente la micropolítica dominante y desestabilizando la subjetividad inherente. En esta dimensión el cuerpo es primordial (Varela y Cohen, 1989) ${ }^{16}$.

Besoain, Cuevas, Araya, Angulo y Morales (2019) en línea con el trabajo de Pakman, colocan en el centro de la reflexión clínica "la pregunta por el sentido en tanto acontecimiento central de todo proceso de subjetividad" (p. 85-86). El sentido está en exceso al significado. El sentido acaricia al cuerpo, pero no cuerpos aislados, "los cuerpos, ya sean personas, ideas, o cosas, tocan otros cuerpos sin poder jamás incorporarlos sino, por el contrario, afirmando su exterioridad. El sentido se "hace" mientras que el significado se puede "tener". Los cuerpos son la materialidad del sentido" (Pakman, 2014, p. 87). Besoain et al. (2019) se preguntaron por las prácticas terapéuticas que promueven movimientos entre micropolítica y poética en terapia. Dieron cuenta de prácticas terapéuticas que bien dialogan con una aproximación genealógica: campo atencional, actitud y técnica (Besoain et al., 2019).

El campo atencional alude a una orientación al sentido a diferentes texturas en el encuentro terapéutico imposibles de representar del todo (palabras, gestos, miradas, suspiros, silencios, sensaciones, imágenes, etc.). No es ajustar la mirada, sino atender a los atractores de la materialidad del decir que atraen la mirada en el encuentro. La actitud: "Entendida como el despliegue estético-corporal, espacial, que acompaña el acontecer del campo atencional" (Besoain et al., 2019, p. 89). Este ámbito promueve una estética terapéutica, una modulación corporal y emocional que no recae en el o la terapeuta, también en la respuesta de los otros en un mutuo comparecer (Pakman, 2014). La técnica pensada no como medio instrumental para un fin, sino desde la distinción heideggeriana, como una práctica que desoculta en parte la realidad desde el encuentro.

Estas prácticas terapéuticas van acompañadas de una actitud curiosa (Cecchin, 1989) y lúdica mediante el uso de metáforas (Carreón, 2014), pero fundamentalmente por el proceso de imaginación: "toda aparición del sentido que es el mundo es un venir a la presencia como un evento singular. El sentido es para nosotros, expuestos al mismos, el venir a la presencia de la realidad del mundo mismo y esa aparición es justamente lo que Nancy considera que es una imagen" (Pakman, 2014, p. 96). El sentido viene a la presencia, en el encuentro en forma de imágenes. No desestimarlas es clave para evitar la mera representación de la experiencia. La imagen es lo distinto dice Jean-Luc Nancy, escapa a toda representación: "La imagen siempre es sagrada" (Nancy, 2002, p. 9).

Una aproximación no solo deconstructiva, sino genealógica orientada al texto como a la dimensión del sentido nos impulsará a esa desestabilización y nuevos espacios para la creatividad y libertad ${ }^{17}$. Mientras que la deconstrucción como práctica terapéutica busca subvertir realidades y experiencias descontadas en los relatos (White, 2004) propios del texto y las dinámicas de poder del contexto, la genealogía persigue las fuerzas en pugna en torno al cuerpo. Lo común es que ambas obran con las escrituras. Asimismo, ni la deconstrucción ni la genealogía están tras un secreto esencial detrás de las cosas o en el origen de las experiencias. $\mathrm{La}$ genealogía señala cómo las cosas mismas fueron construidas pieza por pieza y poseen fechas (Foucault, 2008a). Ambas buscan en las grietas de los signos y recovecos del tiempo; pero la genealogía también en las comisuras del cuerpo.

"Antes se romperá una pierna que romperse una palabra" (Nietzsche, 2011a, p. 105). Por lo mismo, es necesario atender no solo a la dimensión narrativa representativa de la experiencia, sino orientarse al cuerpo y el sentido, a partir de prácticas terapéuticas guías. La exploración genealógica posee una fuerza potencial para trizar, momentáneamente, la subjetividad. El deber de la genealogía dialoga con lo propuesto por la práctica narrativa como la psicoterapia crítico-poética respecto de las palabras; el significado, la experiencia, la dimensión del sentido y el cuerpo. En una fórmula: percibir la singularidad de los sucesos alrededor del sufrimiento y la subjetividad.

\section{DISCUSIÓN}

Proponemos una práctica psicoterapéutica situada, es decir, en toma de posición respecto no solo a su procedencia, sino también a su presencia como espacio de poder. En el encuentro terapéutico existe una potencialidad única para considerar crítica y éticamente nuestros procedimientos y ejercicios habituales, así como oportunidades para moverse en función de una continuidad del poder de los pacientes. El poder y el saber no son moralmente malvados, así como las micropolíticas en las que nos desplazamos habitualmente no son 
nuestras enemigas contra las que habría que luchar destruyéndolas (Pakman, 2011). Son precisamente espacios de continuidad de sentidos múltiples que nos proporcionan identidades múltiples.

La genealogía nos permite entender no solo que las prácticas terapéuticas, modelos clínicos y la psicología en general, poseen una procedencia y una emergencia, también es posible emplazar aquellas prácticas considerando la producción de subjetividad. También, la genealogía irradia una fuerza que es capaz de impulsarnos a una forma de aproximación clínica a partir de nuestras prácticas terapéuticas. En tanto método o actitud toma distancia respecto de la vida. Esa lejanía es indispensable a nuestro entender para el ejercicio clínico crítico.

La práctica terapéutica también es una forma de tecnología del yo y una psicopolítica. Como arte de la vida es capaz de ampliar espacios de libertad relacionales. Sin embargo, esa ampliación de libertad no solo debe regirse por una escucha atenta al interior de los pacientes, sino al afuera que los sostiene. Emplear la mirada hacia las dinámicas intercruzadas por una interioridad íntima y una exterioridad espaciada que mutuamente se constituyen, requiere de una aproximación genealógica para los pliegues de la subjetividad en el sentido deleuzeano (Deleuze, 2015).

Hacer psicoterapia es una forma de práctica genealógica. La genealogía proporciona un camino y una apertura. Este camino en el que convergen terapeutas y pacientes, requiere de la fuerza de la genealogía para descubrir no un origen unívoco, sino múltiples acontecimientos y experiencias, aunque singulares, conectadas. Crea el origen sin inventarlo, pero sobre todo crea vida futura. Si de algo se trata la actividad genealógica es de crear.

A partir de las huellas en el cuerpo, el lenguaje, la imaginación y el sentido, que crean nuestros mundos compartidos, reconocemos que el sometimiento y la subjetividad son inevitables, precisamente nos sujetan a la existencia a veces como única respuesta posible ante eventos adversos propios de estar vivos y en relación con otros y el mundo mismo. Pero, a partir de la procedencia y la emergencia, la genealogía nos encamina a pensar "puntos de vista de apreciación", es decir, crear nuevas valorizaciones al revisar los procesos de subjetivación. Esa creación conlleva la promesa de nuevos modos de ser y una invitación a distintos espacios de libertad.
La psicoterapia como expresión genealógica contribuye a afectar la subjetividad. De esta manera, es una práctica de poder en vías de potenciar la soberanía personal. Pero no es posible obviar que en tanto sujetos estamos expuestos al afuera. El discurso neoliberal nos ilusiona con la libertad individual, cuando en realidad somos sujetos de rendimiento y consumo, al mismo tiempo sujetos de una biopolítica que ejerce una fuerza civilizatoria sobre el animal humano (Lemm, 2010, 2013). El sujeto de sufrimiento es un animal laborans (Han, 2019). La psicoterapia, desde un punto de vista genealógico, también debe tener en consideración este punto esencial: el cuerpo en el que se inscriben los sucesos y acontecimientos es un cuerpo animal. La genealogía es una actitud que prodiga un cuidado animal del otro.

Creemos que la psicoterapia no es solo el lugar del logos, la razón, la interpretación del inconsciente, la primacía del lenguaje, menos un reservorio de técnicas, todos artefactos de un arte valioso. También es el encuentro con la animalidad humana. Precisando, con el sufrimiento del animal que posee lenguaje. Ese animal vive enredado en las preguntas: “¿Para qué sufrir?” “ “¿Quiénes somos?”. Pero ¿de qué es capaz todavía el animal humano? Aventurándonos en deslizar una idea, creemos que no solo de resistir y crear, sino de donar: el animal humano es todavía un artista a quien le es lícito hacer regalos ${ }^{18}$.

El pensamiento de la animalidad para el mundo de la psicoterapia está todavía por venir. $\mathrm{La}$ filosofía de la animalidad no es nueva. En medio de esa recuperación animal encontramos reflexiones necesarias como la lectura de Derrida (2008) ante la displicencia filosófica frente al animal, que ha elevado el espíritu humano -tradición humanistaa una superioridad natural a priori. Asimismo, en Lo abierto, Agamben (2006) tensiona la lectura de Heidegger sobre la cuestión animal, por medio de la relación y resonancia entre la "pobreza de mundo" (Weltarmut) y el "aturdimiento" (Benommenheit) del animal, frente al ser humano como "formador de mundo" (Weltbildend) y su tonalidad emotiva fundamental el "aburrimiento profundo" (Tiefe Langeweile). Además, Esposito (2006) reconoce en Nietzsche una lectura biopolítica afirmativa que no niega las formas múltiples de vida, a partir de una "animalización humana" y como parte no de una "política sobre la vida", sino una "política de la vida". 
Consideramos clave la lectura que Lemm (2010) recoge de la obra de Nietzsche. Profundiza en la diferencia entre la cultura y la civilización desde una lectura biopolítica afirmativa (Lemm, 2010, 2013, 2015). La civilización (propia del Estado moderno) es una forma de violencia contra el animal humano. Al contrario, la cultura, permitiría el cultivo de la animalidad no como un retorno a lo salvaje, sino como una resistencia a la domesticación de formas de vida múltiple. En la potencialidad del olvido animal (Lemm, 2010, 2013) hay una apertura en repensar el animal humano desde una práctica del cuidado de sí orientada a formas de vida diferentes.

En esta tradición antihumanista la animalidad no es metafórica. La genealogía como aproximación al cuidado animal permitiría encontrar fisuras ante la domesticación de la animalidad de los seres humanos. La genealogía desde una mirada clínica puede contribuir a ese cuidado desde la apertura, creación y revalorización de sentidos. En la animalidad y la genealogía hay pistas para una psicoterapia orientada a la singularidad que prioriza las relaciones con el mundo y los otros, más allá de las abstracciones científicas, lingüísticas y metafísicas civilizadas. En la genealogía está la potencialidad de que el conocimiento y la verdad afecten al sujeto relacional tanto en cuerpo como en alma. La psicoterapia es capaz de un compromiso con la cultura y la vida. La genealogía como apertura está orientada al animal humano sufriente y la psicoterapia debe pensarse como una forma hospitalaria para su acogida. 


\section{REFERENCIAS}

Agamben, G. (2006). Lo abierto. El hombre y el animal. Buenos Aires: Adriana Hidalgo.

Anderson, H. y Goolishian, H. (1988). Human Systems as Linguistic Systems: Preliminary and Evolving Ideas about the Implications for Clinical Theory. Family Process. 27 (4), 371-394.

Anderson, H. y Goolishian, H. (1996). El experto es el cliente: La ignorancia como enfoque terapéutico. En McNamee, S. y Gergen, K. (ed.). La terapia como construcción social (pp. 4559). Barcelona: Paidós.

Anderson, H. (2007). Terapias construccionistas sociales postmodernas. Hipnopolis. 5 (4), 2-34.

Anderson, H. (2012). Collaborative Relationships and Dialogic Conversations: Ideas for a Relationally Responsive Practice. Family Process, 51 (1), 1-20.

Bertrando, P. y Toffanetti, D. (2004). Historia de la terapia familiar: los personajes y las ideas (1era ed.). Barcelona: Paidós.

Bertrando, P. (2011). El diálogo que conmueve y trasforma. (1era ed.). México: Pax México S.A.

Besoain, C., Cuevas, P., Araya, C., Angulo, S., y Morales, R. (2019). Consideraciones crítico-poéticas para pensar la clínica sistémica relacional: propuesta metodológica para investigación en psicoterapia. Rev.CES Psico, 12 (2), 83-102.

Carreón, J. (2014). Las metáforas como guías lúdicas para la exploración y la emergencia de nuevas narrativas en el espacio terapéutico: ideas intempestivas nietzscheanas para pensar la práctica clínica sistémica. Límite. Revista Interdisciplinaria de Filosofía y Psicología, 9 (29). 147-179.

Cecchin, G. (1989). Hypothesizing, Circularity, and Neutrality Revisited: An Invitation to Curiosity. Family Process, 26, 405-413.

Deleuze, G. (2008). Nietzsche y la Filosofía (8va ed.). Barcelona: Anagrama.

Deleuze, G. (2015). La subjetivación. Curso sobre Foucault. Tomo III (1era ed.). Buenos Aires: Cactus.

Derrida, J. (1997). Carta a un amigo japonés. Traducción de Cristina de Peretti, en El tiempo de una tesis: Deconstrucción e implicaciones conceptuales (pp. 23-27). Barcelona: Proyecto A Ediciones.

Derrida, J. (2008). El animal que luego estoy si(gui)endo. Madrid: Editorial Trotta.

Dreyfus, H. y Rabinow, P. (2001). Michel Foucault: Más allá del estructuralismo y la hermenéutica (1era ed.). Buenos Aires: Nueva visión.

Esposito, R. (2006). Bios. Biopolítica y filosofía (1era ed.). Buenos Aires: Amorrortu.

Foucault, M. (1969). Nietzsche, Freud, Marx. Revista Eco, $\mathrm{N}^{\circ} 113 / 5$, t. XIX, No 5,6 y 7, 31-48.

Foucault, M. (2008a). Nietzsche, la genealogía, la historia (1era ed., 6ta imp.). Barcelona: Pre-Textos.

Foucault, M. (2012). Vigilar y castigar. Nacimiento de la prisión (2da ed., 4ta reimp.). Buenos Aires: Siglo Veintiuno Editores.

Foucault, M. (2001a). El sujeto y el poder. En Dreyfus, H. y Rabinow, P. (2001). Michel Foucault: Más allá del estructuralismo y la hermenéutica (pp. 241-259). (1era ed.). Buenos Aires: Nueva visión.

Foucault, M. (2001b). Defender la sociedad: Curso en el Collège de France 1975-1976 (1era ed., 2 ${ }^{\mathrm{a}}$ reimp.). Buenos Aires: Fondo de Cultura Económica.

Foucault, M. (2005). Historia de la sexualidad. Volumen 1. La voluntad de saber (1era ed., $2^{\text {a }}$ reimp.). Buenos Aires: Siglo XXI.

Foucault, M. (1987). Historia de la sexualidad. Volumen 3. La inquietud de sí (1era ed.). Madrid: Siglo XXI.

Foucault, M. (2006). Seguridad, territorio, población: Curso en el Collège de France 1977-1978 (1era ed., 2ª reimp.). Buenos Aires: Fondo de Cultura Económica.

Foucault, M. (1994). Hermenéutica del sujeto. Madrid: La piqueta.

Foucault, M. (2008b). Tecnologías del yo. Y otros textos afines (1era ed.). Buenos Aires: Paidós.

Guattari, F. y Rolnik, S. (2019). Micropolítica. Cartografías del deseo (2da ed.). Buenos Aires: Tinta Limón.

Han, Byung-Chul (2014). Psicopolítica. Neoliberalismo y nuevas técnicas de poder. Barcelona: Herder.

Han, Byung-Chul (2019). La sociedad del cansancio. Barcelona: Herder.

Han, B. (2019). Sobre el poder (1era ed., 5ta reimp.). Barcelona: Herder.

Hermans, H. (2001). El Self Dialógico: Hacia una teoría de posicionamiento personal y cultural. Culture y Psychology, 7 (3), 243-281.

Lemm, V. (2010). La filosofía animal de Nietzsche. Cultura, política y animalidad del ser humano (1era ed.). Santiago: Ediciones Universidad Diego Portales.

Lemm, V. (2013). Nietzsche y el umbral biológico de la política moderna. Foucault y la cuestión del animal. En Lemm, V. (2013). Nietzsche y el pensamiento político contemporáneo (pp. 171-193) (1era ed.). Santiago: Fondo de Cultura Económica.

Lemm, V. (2015). Nietzsche y la biopolítica: cuatro lecturas de Nietzsche como pensador biopolítico. Ideas y Valores, 64 (158), 223-248.

Limón, G. (2005). El giro interpretativo en psicoterapia: terapia, narrativa y construcción social (1era ed.). México: Pax México.

McNamee, S. y Gergen, K. (1996). La terapia como una construcción social. Barcelona: Paidós.

Morales, R. (2010). Psicoterapia sistémica, micropolítica y subjetividad: alcances en torno a la formación. En Felipe Gálvez (Comp.) Formación en y para una psicología clínica (pp. 45-67). Santiago de Chile: Colección Praxis Psicológica-Universidad de Chile, 2010.

Nancy, J.L. (2002). La imagen - Lo distinto. Revista Laguna, $11,9-22$.

Nietzsche, F. (2003a). La filosofía en la época trágica de los griegos (3era ed.). Madrd: Valdemar.

Nietzsche, F. (2010a). Sobre la utilidad y los perjuicios de la historia para la vida (4ta ed.). Madrid: EDAF S.A. 
Nietzsche, F. (2007a). Humano, demasiado humano. Un libro para espíritus libres. Volumen I (3era ed.). Madrid: Ediciones Akal, S.A.

Nietzsche, F. (2011a). Aurora (6ta ed.). Madrid: EDAF S.A.

Nietzsche, F. (2007b). Así habló Zaratustra. Un libro para todos y para nadie (1era ed.). Santiago: Gabriela.

Nietzsche, F. (2011b). Genealogía de la moral. Un escrito polémico (3era ed.) Madrid: Alianza.

Nietzsche, F. (2010b). El anticristo. Una crítica del cristianismo (27ava ed.). Madrid: EDAF S.A.

Nietzsche, F. (2013). Crepúsculo de los ídolos. Como se filosofa con el martillo (3era ed.). Madrid: Alianza.

Nietzsche, F. (2003b). Ecce Homo. Madrid: Edimat Libros, S.A.

Pakman, M. (2011). Palabras que permanecen, palabras por venir. Micropolítica y poética en psicoterapia (1era ed.). Barcelona: Gedisa.

Pakman, M. (2014). Texturas de la imaginación. Más allá de la ciencia empírica y del giro lingüístico (1era ed.). Barcelona: Gedisa.

Rober, P. (2005). The Therapist's Self in Dialogical Family Therapy: Some Ideas About Not-Knowing and the Therapist's Inner Conversation. Family Process, 44, 477-495.

Rodríguez-Bustamante, A. (2016). La comunicación familiar. Una lectura desde la terapia familiar sistémica. Revista Latinoamericana de Estudios de Familia, 8, 26-43.
Seikkula, J. (2011). Becoming Dialogical: Psychotherapy or a Way of Life? The Australian And New Zealand Journal Of Family Therapy, 32 (3), 179-193.

Tarragona, M. (2013). Terapia narrativa: reescribir nuestras historias para ser como preferimos ser. En Roizblatt, A. (2013). Terapia de familia y pareja (pp. 178-200). (1era ed.). Chile: Mediterráneo Ltda.

Vicencio, J. (2013). Prácticas sistémicas: arte y oficio. En Roizblatt, A. (2013). Terapia de familia y pareja (pp. 17-31). (1era ed.). Chile: Mediterráneo Ltda.

Varela, F. y Cohen, A. (1989). El cuerpo evocador: una relectura de la inmunidad. En Varela, F. (2016). El fenómeno de la vida (pp. 107-129). Santiago: J.C. Sáez editor.

Vignale, S. (2014). Foucault, actitud crítica y subjetivación. Cuadernos de Filosofía. Universidad Nacional del CUYO (61) 5-17.

White, M. y Epston, D. (1993). Medios narrativos para fines terapéuticos. Barcelona: Paidós Ibérica.

White, M. (2004). Guías para una terapia familiar sistémica. Barcelona: Gedisa.

Zamorano, C. (2014). Consideraciones conceptuales en Francisco Varela para una clínica relacional del sentido. [Tesis de Doctorado, Universidad de Chile]. Repositorio Universidad de Chile. 


\section{NOTAS}

1 Véase Nietzsche (2011b) la Genealogía de la moral publicada en 1887. En ella se cuestiona el supuesto valor unívoco, metafísico, de la moral basada en la compasión no-egoísta. El análisis genealógico mostró la "psicología del sacerdote" y al "animal humano" como un ser existente sin sentido fijo ni meta alguna. En palabras de Nietzsche un "animal enfermizo" pero no por existir ni sufrir, sino porque no ha encontrado la respuesta a la pregunta: “¿Para qué sufrir?”.

$2 \quad$ Nietzsche (2010a) Sobre la utilidad y los perjuicios de la historia para la vida. Segunda consideración intempestiva publicada en 1874. Foucault (2008a) reconoce en la Genealogía de la moral un regreso de Nietzsche "metamorfoseando" los tres modos de historia: monumental, anticuaria y crítica.

3 Nietzsche (2011a). Aurora, § 47 "origen y significación".

4 Para profundizar la cuestión del método y las diferencias analíticas entre arqueología y genealogía, véase Dreyfus, H. y Rabinow, P. (2001). Michel Foucault: Más allá del estructuralismo y la hermenéutica.

$5 \quad$ Nietzsche (2003a) La filosofía en la época trágica de los griegos. De Heráclito recoge la idea de la guerra, la lucha, el conflicto, como movimiento de la vida. Esta posee un fondo agonístico. Un solo mundo de acción en el que lo múltiple y el cambio son parte de la unidad del todo. En este sentido la vida es una lucha no solo producto del azar, sino como inocencia del devenir.

$6 \quad$ Nietzsche (2010b). El anticristo. Una crítica del cristianismo.

7 A modo de ejemplo Nietzsche (2007a) Humano, demasiado humano, primera parte $\S 18$ "Cuestiones fundamentales de la metafísica". Nietzsche (2011a) Aurora, § 102 "Los juicios morales más antiguos". En Crepúsculo de los ídolos "El problema de Sócrates", Nietzsche (2013) concibe al filósofo ateniense como un gran erótico que tuvo necesidad de la razón para dominar sus instintos.

8 Véase Foucault (1969) Nietzsche, Freud, Marx. Conferencia de 1964 en la que aborda el problema de la interpretación. $9 \quad$ Nietzsche (2007b). Así habló Zaratustra. Un libro para todos y para nadie.

10 A modo de ejemplo: sujetos sexuales, de deseo y placer, sujetos laborales, de trabajo y rendimiento, sujetos de consumo, obediencia, alimentación, etc. Diversas formas de producción de subjetividad coexisten.

11 Byung-Chul Han (2019) en La sociedad del cansancio ha planteado una hipótesis acerca de las sociedades actuales postdisciplinarias. Son mundos basados en el rendimiento, con exceso de positividad, información y transparencia. Todo está expuesto, sin negatividad. Nos encontraríamos en una crisis de la libertad, coerción y libertad; coinciden, amo y esclavo también: el sí mismo sin represión externa vive una libertad paradójica en donde el éxito y el fracaso dependen de un yo fragilizado. Se trata de sujetos de rendimiento y consumo despolitizados: animal laborans. El neoliberalismo produce sujetos agotados, cansados y deprimidos. 12 Las tecnologías del yo (Foucault, 1987, 2008b, 1994) se remontan a la cultura griega y romana. Su procedencia se retrotrae

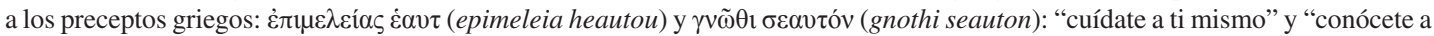
ti mismo". Este último terminó por desplazar y silenciar al primer principio también traducido como "ocupación de sî́", "inquietud de sî" o "cuidado de sî". Ambos se relacionan con el gobierno de sí que los griegos practicaban en la Antigüedad como formas de cultivo de la virtud - $\dot{\alpha} \rho \varepsilon \tau \eta ́$ o areté-. Preparándose para el gobierno de los otros y de las polis, el cuidado de sí es una práctica espiritual de acceso a la verdad mediante un Otro. Ese otro era un maestro.

13 En 1965, Alan Badiou le pregunta a Michel Foucault ¿Qué es la psicología? Su respuesta apunta a considerar la psicología, producción humana, no como una forma de objetividad ni cientificidad, sino interrogarla como cualquier otra forma cultural.

14 Byung-Chul Han (2019) en su libro Psicopolítica dice: "La psicopolítica neoliberal es la técnica de dominación que estabiliza y reproduce el sistema dominante por medio de una programación y control psicológicos. El arte de la vida como praxis de libertad tiene que adoptar la forma de una des-psicologización. Desarma la psicopolítica como medio de sometimiento. Se des-psicologiza y vacía al sujeto con el fin de que quede libre para esa forma de vida que todavía no tiene nombre" (p. 117).

15 En la Genealogía de la moral, tratado primero, Nietzsche (2011b) agrega respecto de la ficción del agente y del sujeto: "no hay ningún 'ser' detrás del hacer, del actuar, del devenir; el 'agente' ha sido ficticiamente añadido al hacer, el hacer es todo" (p. 67).

16 Véase Varela y Cohen (1989). El cuerpo evocador: una relectura de la inmunidad. En Varela, F. (2016). El fenómeno de la vida (pp. 107-129). Santiago: J.C. Sáez editor.

17 No es nuestra intención problematizar ni profundizar acerca de la compleja diferencia o relación entre deconstrucción y genealogía. Derrida (1997) menciona que la deconstrucción no es la operación de un sujeto, tampoco un análisis ni una crítica, más bien se trata de un acontecimiento. Para Foucault (2008a) la genealogía es un método.

18 Vanessa Lemm (2010) realiza una lectura de la filosofía nietzscheana a base de la animalidad. Reconoce al Zaratustra de Nietzsche como la personificación de la donación como virtud que hace justicia. Zaratustra se dona a sí mismo: "la expresión "el honesto regalo al huésped [rechtschaffendes Gastgeschenk]' (Z "El saludo"): es decir, un don que hace justicia (schafft Recht); un don que hospeda, que hace lugar y recibe al otro de manera justa" (p. 178-179). 